\title{
Empirical Study on Pricing of Structured Products with Martingale Theory
}

\author{
Chen Si-liang ${ }^{1, *}$, Peng Long ${ }^{2}$ and Zeng Jian-qiu ${ }^{1}$ \\ ${ }^{1}$ Beijing University of Posts and Telecommunications, P.O. Box 178, Beijing, China; ${ }^{2}$ Beijing Foreign Studies Universi- \\ ty, P.O. Box 117,Beijing, China
}

\begin{abstract}
This paper focuses on the pricing of CSI 300 index-linked structured products with barrier option attached to call option. "Huiying No.198 of Huaxia Bank" was characterized by one index linked \& multiple observations, and priced by means of the martingale theory. The pricing formula of barrier option attached to call option was simplified by Girsano conversion of $\mathrm{P}$ and $\mathrm{R}$ measures. The option price was calculated through conversion application of Girsanov Lemmas. The result demonstrates that the theoretical premium rate of Huiying No.198 is $1.4 \%$ and martingale theory provides a concise and straightforward method.
\end{abstract}

Keywords: Barrier option, girsanov theorem, martingale theory, pricing, structured products.

\section{INTRODUCTION}

Under inflation and low interest rates on deposits, the actual rate of return for investors is negative. While the stock market is high-risk, investors invest in structured products [1] in order to obtain a high return while bearing a relatively low risk. The research of pricing of structured products would help investors choose the right structured products, help issuers price structured products and be conducive to national regulation of structured products.

Chen and Sears [2] decomposed spin (standard \& Poor's 500 index Subordinated note) into bonds and European call option, and put forward the pricing model: the theoretical value of spin = zero coupon bond value $+($ the value of $S \&$ P500 index option $x$ multiplier). Chen and Kensinger [3] proposed a payoff formula of MICDs (Market-Index Certificates of Deposits): $1+\min \left\{K, \max \left[\lambda, \theta\left(S_{1} / S_{0}-1\right)\right]\right\}$, and the value equation of MICDs was derived from decomposition technique and the maximum and minimum optimization model, the pricing and hedging studies were conducted, empirical studies showed that some SPs were overpriced. Finnerty [4] decomposed sign into zero coupon bonds and European calls, and drew the following model: the theoretical value of sign $=$ zero coupon bond's value + call option's value + tax deferred income + transaction costs and the value of innovation. Pavel a. Stoimenov, Sascha Wilkens [5] studied equity-linked SPs in Germany, the result demonstrated that equity-linked SPs in the German primary market were overpriced, and the theoretical price were the same as the transaction price at the mature and perfect.

German secondary market. Diethelm and Wallmeier [6] priced convertible bonds with multiple assets, the result was that 468 multi-asset reverse convertible bonds with knockout feature in Switzerland averaged the premium rate of at least 3.4\%. Renmin and Chen Jinlong [7] analysed the structure of equity-linked guaranteed structured financial products of foreign exchange, and priced it by means of the BlackScholes option pricing method.Chen Jinlong, Renmin [8] studied the single asset equity-linked guaranteed structured financial products with hypothesis of "without limit of return rate" and "limit of return rate" and "proportional transaction costs ", and obtained the formula with the impact of exchange rate and without the impact of exchange rate, and priced "CITIC CSI 300 index-linked No. 1 financial products of RMB". The result demonstrated that the yield design was reasonable. Chen Jinlong, Renmin [9] priced the multiple assets equity-linked guaranteed structured financial products -"Shenzhen bank Yingfeng 0706" by means of the Monte Carlo method, pointed out the revenue function important, and released the relationship between assets by means of Cholesky decomposition method. The result demonstrated that the price of SPs was high, while the actual rate was low. Guan Chang [10] priced one kind of convertible bonds by means of Martingale theory. Tian Hui [11] priced "Huaxia bank Hui ying No. 1" by means of Cholesky decomposition method and the Monte Carlo method.

This paper would make use of martingale theory to price "Huiying No. 198 of Huaxia Bank" which was characterized by CSI 300 index linked \& multiple observations. Conversion of $\mathrm{P}, \mathrm{Q}$ and $\mathrm{R}$ measures simplified the pricing formula of barrier option attached to call option. The option price was calculated by conversion application of Girsanov Lemmas and MATLAB 2013.

\section{METHODS}

The martingale theory as a main basis of option pricing. provides a simple and easy method to understand the pricing of derivatives. In financial analysis, expected values usually 
are represented by the process of price movement, and martingale is used to define conditional mathematical expectation, so martingale and other mathematical concepts could describe the characteristics of price process of the financial assets.

Martingale quickly became one of the frontier research in financial economics. In the 1970s, Strasbourg (France), improved Brownian motion stochastic integral into the semimartingale stochastic integrals and promoted the martingale theory and stochastic process in option pricing. Martingale theory into a financial option pricing model was solved. Harrison in collaboration with Pliska and Kreps respectively, published two articles about the theory of martingale into option pricing. These two articles laid a solid foundation to apply martingale theory into option pricing and provided a new idea and a new method for option pricing model

\subsection{Girsanov Theorem [12]}

Let $(\Omega, F, P)$ be a probability space, if $\theta_{0 \leq t \leq T}$ is an adaptation process to meet $\int_{0}^{t} \theta_{S}^{2} d s<\infty$, and $L_{t}$ is a martingale

$L_{t}=\exp \left(-\int_{0}^{t} \theta_{S} d W_{S}^{P}-\frac{1}{2} \int_{0}^{t} \theta_{S}^{2} d s\right)$

Among them, $\left\{\mathrm{W}_{\mathrm{t}}^{\mathrm{P}}, 0 \leq \mathrm{t} \leq \mathrm{T}\right\}$ is the standard onedimensional probability space of the Brown movement, and then let

$d Q=L_{t}$

Then under the probability measure $\mathrm{Q}$, defined

$W_{t}^{*}=W_{t}+\int_{0}^{t} \theta_{S} d S$

The random process $\left(\mathrm{W}_{\mathrm{t}}^{*}\right)_{0<t \leq T}$ is an standard Brown movement within $\left(\Omega, F_{t}, P^{L}\right)$, and

$E^{Q}\left(I_{A}\right)=E^{P}\left(L_{t} I_{A}\right)$

For $\forall A \in F$ are established. Among them, $E^{P}$ is the expectation under $P$ measure, $E^{Q}$ is the expectation under $\mathrm{Q}$ measure, I is an indicator function.

\subsection{The Conversion Application of Girsanov Theorem}

Let $(\Omega, F, P)$ is a probability space, $F$ is $\sigma$-algbra which is composed of some subset of $\Omega,\left\{W_{t}^{P}, 0 \leq t \leq T\right\}$ is the probability space of one dimensional standard Brownian motion, $F_{t}$ is a natural $\sigma$-algebra which is generated by $\mathrm{W}_{\mathrm{t}}^{\mathrm{P}}$. The price of the underlying asset is as follow:

$d S_{t}=\mu S_{t} d t+\sigma S_{t} d W_{t}^{P}(0 \leq t \leq T)$

Among them, $S_{t}$ represents the stock price at time t; $\mu$ is expected stock return; $\sigma$ is volatility; $\mu$ and $\sigma$ are constant; $d W_{t}^{P}$ is a Brownian motion moment increment at time t under the probability measure $P$.

$d \ln S_{t}=\left(\mu-\frac{1}{2} \sigma^{2}\right) d t+\sigma d W_{t}^{P}$

$S_{T}=S_{0} \exp \left(\mu-\frac{1}{2} \sigma^{2}\right) d t+\sigma \Delta W_{T}^{P}$

Among them, $\Delta W_{t}^{P}=W_{t}^{P}-W_{0}^{P}$ obeys normal distribution $N(0, T), W_{T}^{P}$ is Brownian motion value at time $T$ under $P$ measure. $W_{0}^{P}$ is the initial value.

\subsection{The First Conversion of $P$ measure and $Q$ measure}

The definition of $\mathrm{Q}$ measure, meet

$$
\begin{aligned}
& \frac{d Q}{d P}=\exp \left(-\int_{0}^{T} \frac{\mu-r}{\sigma} d W_{S}^{P}-\frac{1}{2} \int_{0}^{t}\left(\frac{\mu-r}{\sigma}\right)^{2} d u\right) \\
& \text { Let } \xi_{T}=\exp \left(-\int_{0}^{T} \frac{\mu-r}{\sigma} d W_{S}^{P}-\frac{1}{2} \int_{0}^{t}\left(\frac{\mu-r}{\sigma}\right)^{2} d u\right),
\end{aligned}
$$

Among them, $\mathrm{r}$ is the risk-free interest rate, $\mathrm{Q}$ is the equivalent martingale measure of $\mathrm{P}$ through the Girsanov theorem, and the definition is as follow:

$W_{t}^{Q}=W_{t}^{P}+\int_{0}^{T} \frac{\mu-r}{\sigma} d u=W_{t}^{P}+\frac{\mu-r}{\sigma} t(0 \leq t \leq T)$

The random process $\left(W_{t}^{Q}\right)_{0 \leq t \leq T}$ is the standard Brown movement within $(\Omega, F, P)$. And

$E^{Q}\left(I_{A}\right)=E^{P}\left(\xi_{T} I_{A}\right)$

For $\forall A \in F$ is established. Among them, $E^{P}$ is the expectation under $\mathrm{P}$ measure, $E^{Q}$ is the expectation under $Q$ measure, $\mathrm{I}$ is an indicator function.

Obviously, relationship between the establishment of the following:

$d W_{t}^{Q}=d W_{t}^{P}+\frac{\mu-r}{\sigma} d t$

Substitute (11) into (5):

$d S_{t}=r S_{t} d t+\sigma S_{t} d W_{t}^{Q}$

By (12), according to Ito theorem,

$S_{T}=S_{0} \exp \left[\left(r-\frac{1}{2} \sigma^{2}\right) d t+\sigma \Delta W_{T}^{Q}\right]$

Among them, $\Delta W_{T}^{Q}=W_{T}^{Q}-W_{0}^{Q}$ obeys normal distribution $N(0, T)$.

Because (12) is independent with the expected rate of return which has nothing to do with the risk preferences of investors, so that $\mathrm{Q}$ is risk neutral measure. (1) and (12) shows that: the expected rate of instant reward $\mu$ is replaced by risk-fee interest rate $r$ based on the risk neutral. The volatility $\sigma$ of stock is not affected by the transition of probability measure.

\subsection{The Second Conversion of $Q$ measure and $R$ measure}

$Q$ measure can be converted into R measure by Girsanov theorem. Let,

$$
\begin{aligned}
& \quad \frac{d R}{d P}=\exp \left(\int_{0}^{T} \sigma d W_{S}^{Q}-\frac{1}{2} \int_{0}^{t} \sigma^{2} d u\right)=\exp \left(\sigma \Delta W_{S}^{Q}-\right. \\
& \left.\frac{1}{2} \sigma^{2} t\right)
\end{aligned}
$$

Let, $\quad \xi_{T}=\exp \left(\sigma \Delta W_{S}^{Q}-\frac{1}{2} \sigma^{2} t\right) \quad W_{t}^{R}=W_{t}^{Q}+\int_{0}^{t} \sigma d u=$ $W_{t}^{P}+\frac{\mu-r}{\sigma} t(0 \leq t \leq T)$

By Girsanov's theorem, $\mathrm{R}$ is a probability measure, stochastic process $\left(W_{t}^{R}\right)_{0 \leq t \leq T}$ is a standard Brown movement under $\left(\Omega, \mathrm{F}_{\mathrm{T}}, \mathrm{R}\right)$. And

$E^{R}\left(I_{A}\right)=E^{Q}\left(\xi_{T} I_{A}\right)$ 
For $\forall A \in F$ is established. Among them, $E^{Q}$ is the expectation under $Q$ measure, $E^{R}$ is the expectation under $\mathrm{R}$ measure, $I$ is indicator function. By (4) - easy to get:

$d W_{t}^{R}=d W_{t}^{Q}-\sigma d t$

Substitute (16) into (17)

$d S_{t}=r S_{t} d t+\sigma S_{t} d W_{t}^{Q}$

By (17), according to Ito theorem, thus,

$S_{T}=S_{0} \exp \left[\left(r+\frac{1}{2} \sigma^{2}\right) d t+\sigma \Delta W_{T}^{R}\right]$

Among them, $\Delta W_{T}^{R}=W_{T}^{R}-W_{0}^{R}$ obeys normal distribution $N(0, T)$.

Obviously, the volatility $\sigma$ of stock was not affected by the transition from $\mathrm{Q}$ measure to $\mathrm{R}$ measure.

\subsection{The Conversion Application of Girsanov Lemma 1}

let $Y=\ln \frac{\bar{s}}{S_{0}}, \mu=r-q-\frac{\sigma^{2}}{2}, y$ is the value of barrier. $\bar{S}=\max (S), \mu$ is the cumulative normal distribution expectation, $q$ is the premium rate.

The distribution function of $Y$ is:

$P(Y<y)=N\left(\frac{y-\mu T}{\sigma \sqrt{T}}\right)-e^{2 \mu y / \sigma^{2}} N\left(\frac{-y-\mu T}{\sigma \sqrt{T}}\right)$

\subsection{The Conversion Application of Girsanov Lemma 2}

let $X=\ln \frac{S_{T}}{S_{0}}, Y=\ln \frac{\bar{s}}{S_{0}}, \mu=r-q-\frac{\sigma^{2}}{2}, y$ is the value of barrier. $\bar{S}=\max (S), \mu$ is the cumulative normal distribution expectation, $q$ is the premium rate.

The distribution function of $X \& Y$ is:

$P[X<x, \quad Y<y]=N\left(\frac{x-\mu T}{\sigma \sqrt{T}}\right)-e^{2 \mu y / \sigma^{2}} N\left(\frac{x-2 y-\mu T}{\sigma \sqrt{T}}\right)(20)$

\section{EMPIRICAL TESTS}

3.1. Basic Terms of "Huaxia Bank Hui Ying No.198" Index-linked Guaranteed SPs Introduction

Table 1. Basic terms of "HuiYing No.198".

\begin{tabular}{|c|c|}
\hline Huiying No.198 & $\begin{array}{c}\text { RMB Denominated Notes, with Guaranteed } \\
\text { Profit Limit }\end{array}$ \\
\hline \hline Issuer & Huaxia Bank \\
\hline The date of issue & $\begin{array}{c}\text { From May } 7^{\text {th }}, 2015 \text { to May } 12^{\text {th }}, 2015 \text { (inclu- } \\
\text { sive) }\end{array}$ \\
\hline The investment period & On May $14^{\text {th }}, 2015-$ May $6^{\text {th }}, 2016$ \\
\hline Investment currency & RMB \\
\hline Par value & $\begin{array}{c}\text { As the starting point for the amount of 50000 } \\
\text { RMB, per } 1000 \text { RMB increase }\end{array}$ \\
\hline Underlying Index & CSI 300 index \\
\hline Issued price & $100 \%$ \\
\hline
\end{tabular}

Table 1. Contd......

\begin{tabular}{|c|c|}
\hline Huiying No.198 & $\begin{array}{c}\text { RMB Denominated Notes, with Guaranteed } \\
\text { Profit Limit }\end{array}$ \\
\hline Date of establishment & May $14^{\text {th }}, 2015$ \\
\hline Expiry date & May $10^{\text {th }}, 2016$ \\
\hline $\begin{array}{l}\left(\mathrm{S}_{0}\right) \text { Stock refer- } \\
\text { ence price }\end{array}$ & $\begin{array}{l}\text { The closing price of the date of the establish- } \\
\text { ment (will be postponed to the next trading day } \\
\text { in the case of the stock suspension) }\end{array}$ \\
\hline The final price & $\begin{array}{l}\text { From the date of the closing price on the expiry } \\
\text { date }\end{array}$ \\
\hline Barrier price & $125 \% \times \mathrm{S}_{0}$ \\
\hline Participation rate & $25 \%$ \\
\hline Trading day & $\begin{array}{l}\text { Effective trading day of the provisions of the } \\
\text { Shanghai Stock Exchange }\end{array}$ \\
\hline Observation period & $\begin{array}{l}\text { May } 14^{\text {th }}, 2015 \text { to May } 6^{\text {th }}, 2016 \text {, each trading } \\
\text { day from the establishment date to the settle- } \\
\text { ment date } \\
\text { including. two days of the end }\end{array}$ \\
\hline Guaranteed rate & $100 \%$ \\
\hline $\begin{array}{l}\text { The principal and } \\
\text { interest payment }\end{array}$ & Customers can not be paid in advance. \\
\hline Yield to maturity & $\begin{array}{l}\text { Case 1: if the stock price index in the observa- } \\
\text { tion period has never been greater barrier price; } \\
\text { the expected annual revenue rate (annual) = } \\
2.00 \%+\text { max (the final price / initial price - } \\
100 \%, 0) * \text { participation rate. The participation } \\
\text { rate }=25 \% \text {; } \\
\text { Case } 2 \text { : if the stock price index in the observa- } \\
\text { tion period was greater than the barrier price; } \\
\text { the expected annualized rate of return=3.80\%. } \\
\text { The safety of principal, investment income } \\
\text { depends on the underlying performance in the } \\
\text { future. According to the analysis of the yield, } \\
\text { the best case scenario: investors can obtain the } \\
\text { highest expected annual return rate } 8.25 \% \text {; the } \\
\text { worst case: investors receive expected annual } \\
\text { return rate is only } 2.00 \% \text {. }\end{array}$ \\
\hline
\end{tabular}

\subsection{Case Analysis}

Because Huiying No.198 SPs linked to the stock index and contained barrier option, the paper could price it by means of decomposition method and martingale theory. The theoretical value would be reached using MATLAB 2013.

Assuming that investors invested 50000RMB to buy the SPs on May $14^{\text {th }} 2015$, which was the minimum investment, therefore, 50000RMB was the sales price of commercial banks. The theoretical price of the SPs would be analyzed in the following.

According to the SPs' specifications, the guaranteed rate was $100 \%$, the minimum of return rate was $2 \%$. so the issuer invests in bond or other short-term assets of good security to receive $102 \%$ xprincipal on the expiry date. 


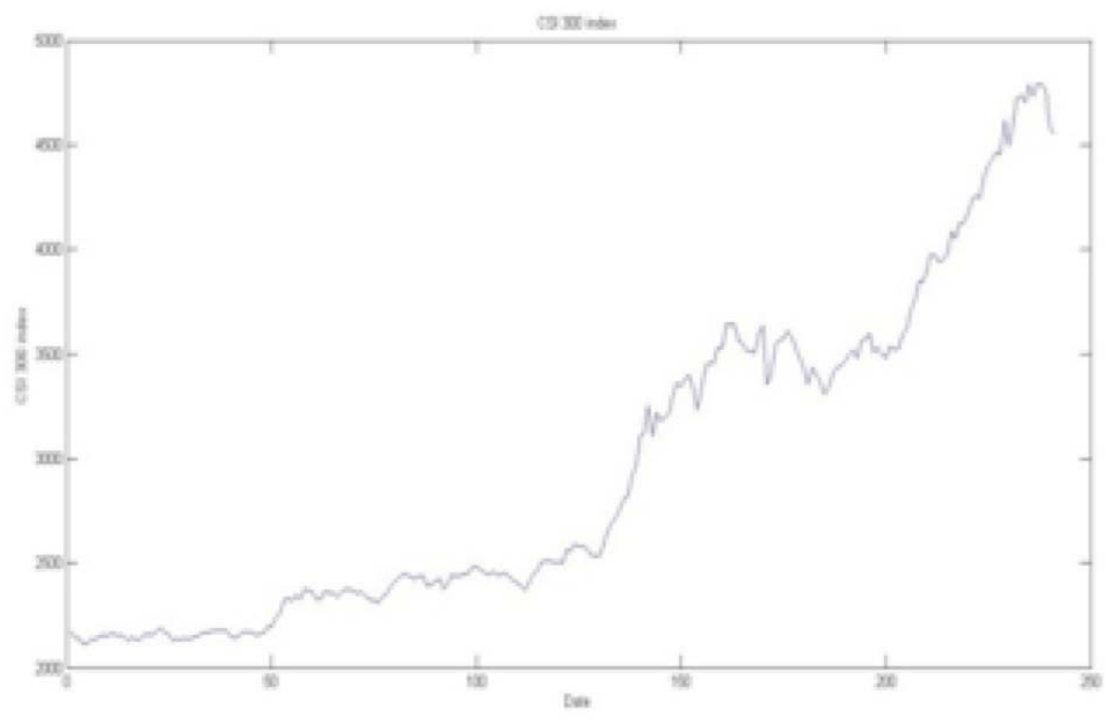

Fig. (1). CSI 300 index from May $14^{\text {th }}, 2014$ to May $6^{\text {th }}, 2015$.

The return of floating portion of the SPs was decided by option pricing. Because the underlying index was CSI 300 index, the derivative was the barrier option [13], the paper could price the SPs by means of martingale theory and MATLAB 2013. Fig. (1) shows CSI 300 index from May $14^{\text {th }}, 2014$ to May $6^{\text {th }}, 2015$.

The initial value of CSI 300 index was $\mathrm{S}_{0}$. The trigger event occured when $S_{i} \geq m \times S_{0}$. Set this trigger event $B$, the payoff function of the financial products was as follow:

payoff $=$

$\left\{\begin{array}{c}D \times(1.02+1.8 \%), \text { if } \max \left(\mathrm{S}_{\mathrm{i}} / S_{0}\right) \geq m \\ D \times\left[1.02+25 \% \times \max \left(\frac{S_{T}}{S_{0}}-1\right)\right], \text { if } \max \left(\mathrm{S}_{\mathrm{i}} / S_{0}\right)<m\end{array}\right.$

Among them, $D:$ Principal, $\tau=5 \%, \gamma=0.36 \%$, $m=1.25$ 。

Thus, investors would get two results from the SPs: if the event B happened, the investment rate was $2 \%+1.8 \%=3.8 \%$, which is greater than the bank deposit rate. If the event B did not happen, investors could only ensure safety of initial principal and obtain a positive profit $2 \%$ and the cap rate was $8.75 \%$. Obviously, by comparing the structure of the SPs and characteristics of barrier option and call option, this type of financial product is embedded with a barrier option attached to call option. So the analysis began from the barrier option features to be carried out.

The SPs could not be redeemed, and its price was dependent on the path of the underlying index's trend. SPs' features were one asset and multi observation periods. It was difficult to price the SPs by means of the common method. The paper would decompose the pricing formula of the barrier option attached to call option by means of martingale theory. Then the sum of barrier option and the discounted value of the fixed income securities price was the theoretical price of this financial product

\subsection{Pricing of Fixed Income Securities}

The revenue of SPs is divided into fixed income and floating income. There are three types of guaranteed fixed type, guaranteed floating type and non-guaranteed type. This product in the paper was guaranteed floating type, then we split it into fixed income and floating income. Fixed income could be used as earnings without risk. Because China's deposit interest rate was controlled, and not fully realized the marketization of interest rate, the one-year deposit interest rate could be regarded as risk-free interest rate. the research base was based on the minimum standard of 50000 RMB.

Set the par value of the bonds $\mathrm{D}$, the interest rate $\mathrm{r}$, bond issuers need to pay a total of $n$ point cash flow to owners. Issuers need to payA $=\mathrm{D} \times \mathrm{r}$ interest payments at $\mathrm{t}=$ $1,2, \ldots, n-1$. Issuers need to pay interest $A=D \times r$ and principal $\mathrm{D}$. Assuming the discounted rate $\mathrm{k}$ within this period, the bond pricing formula was as follow:

$P=\sum_{t=1}^{n-1} \frac{D \times r}{(1+k)^{t}}+\frac{D \times(1+r)}{(1+k)^{n}}$

In the paper, for the sake of simplicity, set the interest rate of bond between a year and two years within the specified period of time as the discounted rate. So the bond pricing can realized accurately.

The fixed income portion is the sum of the principal and interest. We have to calculate the discounted price to price the bond. According to one year time bond interest rate in March, 2015, 3.39\% was the yield to maturity. ${ }^{1}$ from China Ministry of Finance website. The discounted value of $50000 \times(1.02) \mathrm{RMB}$ is $50000 \times(1.02) /(1+3.39 \%)=$ 49327.79RMB. A RMB's discounted present value is $1.02 /(1+3.39 \%)=0.9866 \mathrm{RMB}$.

\subsection{Parameter Determination}

For a period of one year, in order to estimate the benefit of products, this paper selects historical volatility and return rate calculated by closed price of CSI 300 from May 14th 2014 to May 6th 2015. The time distance during the recent

${ }^{1}$ http://www.mof.gov.cn/pub/guokusi/redianzhuanti/guozaiguanli/gzfxpzs/2 01505/t20150504_1226445.html 
period of financial products can effectively reflect index volatility. The paper downloaded CSI 300 index data in sample time interval from Yahoo Finance. Drew the stock chart using MATLAB as shown below.

According to information released by the commercial bank, the initial prices of the CSI 300 index in was $S_{0}=4714.48$, Expiration period $\mathrm{T}=1$ year. The trigger condition was used in the historical data, the stock index hit trigger price was $H_{1}=5893.1$. According to the calculation chart of rough observation and sample data that stock did not trigger price. Although the stock market was bullish in 2015, the stock was at a high risk level, stock index had seldom reached 5893.1 in history. Therefore, Investors expected stock index not high, investors were willing to invest.

Investigation of the CSI 300 index was almost in accordance with normal distribution. According to the sample data, using Quantile-Quantile graph analysis. The result was as shown below:

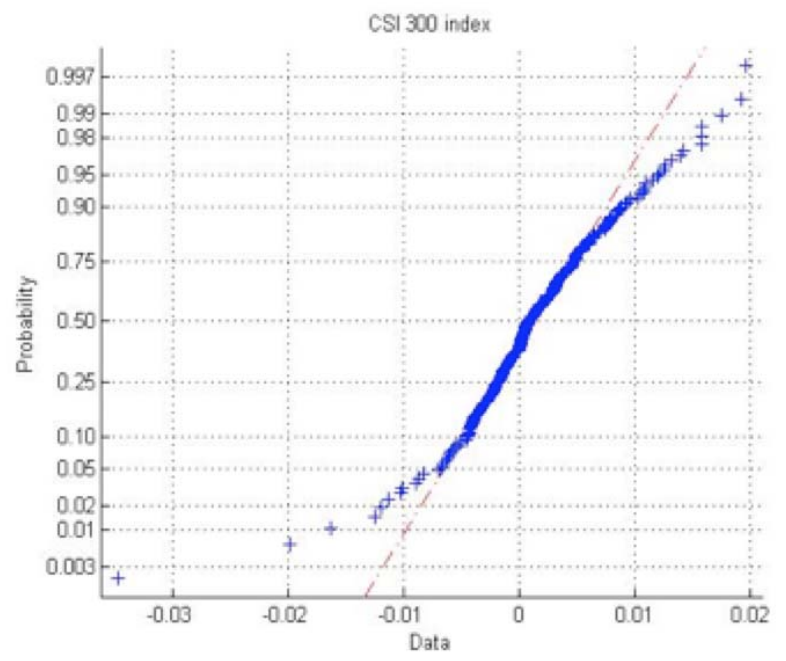

Fig. (2). Quantile-Quantile graph of CSI 300 index.

Conclusion based on the result of Quantile-Quantile: CSI 300 index almost obeyed normal distribution, but refused to accept normal distribution at both ends. Hypothesize the return rate to obey normal distribution in this paper. Fig. (2) shows Quantile-Quantile graph of CSI 300 index.

The floating portion of SPs can be treated as the pricing of a barrier option attached to call option. Then calculated the historical volatility of index rate. Firstly, the closing prices of CSI 300 index from the May 14th, 2014 to May 6th, 2015 were processed by logarithm by the formula (23), CSI 300 index volatility was calculated by the formula (24).

$X_{i}=\ln \left(\frac{P_{i+1}}{P_{i}}\right)=\ln \left(P_{i+1}\right)-\ln \left(P_{i}\right)$

$\sigma=\sqrt{\frac{\sum_{i=1}^{N}\left(X_{i}-\bar{X}\right)^{2}}{N-1}}, \quad \bar{X}=\frac{\sum_{i=1}^{N}\left(X_{i}-\bar{X}\right)^{2}}{N}$

Here, $\mathrm{N}$ was the number of observations of $241, \sigma$ represented logarithmic return average deviation, that was standard deviation. The trading days of Shanghai stock exchange was a total of 252 , so the annualized fluctuation rate was $\sigma \sqrt{252}$. Finally, it was concluded that stocks' year fluctuations in the rate of $: \sigma_{1 \text { year }}^{2}=0.00983752526252664$. one-year deposit interest rate in March, 2015 as the risk-free interest rate was $2.75 \%$, the dividend yield rate was $2.67 \%$. CSI 300 index at the beginning was 4714.48 on May $14^{\text {th }}$, 2015.

\subsection{Pricing the Option}

The pricing formula of barrier option attached to call option was simplified by means of conversion of $\mathrm{P}, \mathrm{Q}$ and $\mathrm{R}$ measures. The option price was calculated through conversion application of Girsanov Lemmas and by MATLAB 2013.

$$
\begin{aligned}
& C=e^{-r T} E^{Q}\left[25 \% \times \max \left[\left(S_{T} / S_{0}-1\right), 0\right] I_{A}\right]+e^{-r T} \times r_{2} \times \\
& E^{Q}\left[I_{B}\right]=25 \% \times e^{-r T} \times E^{Q}\left[\left(S_{T} / S_{0}\right) I_{C}\right]-25 \% \times e^{-r T} \times \\
& E^{Q}\left[I_{C}\right]+e^{-r T} \times r_{2} \times E^{Q}\left[I_{B}\right]=25 \% \times E^{R}\left[I_{C}\right]-25 \% \times e^{-r T} \times \\
& E^{Q}\left[I_{C}\right]+e^{-r T} \times r_{2} \times E^{Q}\left[I_{B}\right]=25 \% \times E^{R}[I(A-D)]- \\
& 25 \% \times e^{-r T} \times E^{Q}\left[I{ }_{(A-D)}\right]+e^{-r T} \times r_{2} \times E^{Q}\left[I_{B}\right]=25 \% \times \\
& {\left[P^{R}(A)-P^{R}(D)\right]-25 \% \times e^{-r T} \times\left[P^{Q}(A)-P^{Q}(D)\right]+} \\
& e^{-r T} \times r_{2} \times P^{Q}(B)= \\
& 25 \% \times\left\{N\left(\frac{y_{1}-\mu_{1} T}{\sigma \sqrt{T}}\right)-e^{2 \mu_{1} y_{1} / \sigma^{2}} N\left(\frac{-y_{1}-\mu_{1} T}{\sigma \sqrt{T}}\right)-\left[N\left(\frac{x-\mu_{1} T}{\sigma \sqrt{T}}\right)-\right.\right. \\
& \left.\left.e^{2 \mu_{1} y_{1} / \sigma^{2}} N\left(\frac{x-2 y_{1}-\mu_{1} T}{\sigma \sqrt{T}}\right)\right]\right\}-25 \% \times e^{-r T} \times\left\{N\left(\frac{y_{1}-\mu_{2} T}{\sigma \sqrt{T}}\right)-\right. \\
& e^{2 \mu_{2} y_{1} / \sigma^{2}} N\left(\frac{-y_{1}-\mu_{2} T}{\sigma \sqrt{T}}\right)- \\
& \left.\left[N\left(\frac{x-\mu_{2} T}{\sigma \sqrt{T}}\right)-e^{2 \mu_{1} y_{1} / \sigma^{2}} N\left(\frac{x-2 y_{1}-\mu_{2} T}{\sigma \sqrt{T}}\right)\right]\right\}+e^{-r T} \times r_{2} \times\{1- \\
& \left.N\left(\frac{y_{1}-\mu_{2} T}{\sigma \sqrt{T}}\right)+e^{2 \mu_{2} y_{1} / \sigma^{2}} N\left(\frac{-y_{1}-\mu_{2} T}{\sigma \sqrt{T}}\right)\right\}=0.0120
\end{aligned}
$$

Among them, $r_{1}=\max \left[\left(S_{T} / S_{0}-1\right), 0\right], r_{2}=$

$$
\begin{gathered}
0.018, \mu_{1}=r-q+\frac{\sigma^{2}}{2}, \quad \mu_{2}=r-q-\frac{\sigma^{2}}{2} \\
\sigma_{1 \text { year }}^{2}=0.00983752526252664, r=\ln (1+ \\
2.75 \%), q=\ln (1+2.67 \%) \\
y_{1}=\ln (1.25), x=\ln 1=0, \\
A=\left[\left(\frac{\bar{S}}{S_{0}}\right)<1.25\right], B=\left[\left(\frac{\bar{S}}{S_{0}}\right) \geq 1.25\right], \\
C=\left[S_{T} \geq S_{0},\left(\frac{\bar{S}}{S_{0}}\right)<1.25\right], \\
D=\left[S_{T}<S_{0},\left(\frac{\bar{S}}{S_{0}}\right)<1.25\right]
\end{gathered}
$$

\subsection{The Price of Financial Products}

After reaching the price of fixed income and floating income, summed them and reached the theoretical value of SPs. The theoretical value of per RMB of "Huiying No.198" is 0.9986 which is the sum of 0.9866 and 0.0120 . The theoretical value of "Huaxia Bank Huiying No.198" is $\mathrm{Val}^{T}=49928 \mathrm{RMB}$ by means of the martingale theory and MATLAB 2013. Relative premium rate by Wilkens and Stoimenov formula:

$r p=\frac{V a l^{M}-V a l^{T}}{V a l^{T}}$

Among them: $\mathrm{Val}^{\mathrm{M}}$ is the market price, $r p$ is the premium rate. When $\mathrm{Val}^{M}=50000, r p=1.4 \%$, and the theoretical premium rate of the SPs is $1.4 \%$, Huaxia Bank would obtain the theoretical premium of $72 \mathrm{RMB}$ after issuing "Huiying No.198"SPs of 50000 RMB. 


\section{CONCLUSION}

This paper induced the pricing formula of barrier option attached to call option. The formula demonstrates that it is concise and straightforward to price some kinds of SPs by means of martingale theory.

The result demonstrates that the premium rate of Huaxia Bank is $1.4 \%$. In fact, three main reasons could benefit the issuer. Firstly, stock market of China is a "policy market", which is not risk neutral, the issuer could forecast with a good accuracy through a deep research on China policy in the non-efficient market. Secondly, there exists a financial phenomenon: the volatility is not an accurate indicator of the slope of the price movement; if the volatility of return rate of CSI 300 index is at a low level, the index can become higher and higher. Lastly, banks could shift short-term rolling bonds into long-term bonds with a operation twist strategy. When the interest rates of the three and five year certificate bonds are $4.92 \%$ and $5.32 \%$, the price of "Hui Ying No.198" would be 49208 RMB and 49024 RMB. Above all, "policy market", "financial phenomenon" and "a shift from short-term bonds into long-term bonds" would make Huaxia bank get a potential high premium rate.

Further study on the pricing of SPs focuses on the volatility estimation and how to improve calculation method, such as using the GARCH model to estimate the volatility, using the dual variable method and control variable method of Monte Carlo simulation to obtain more accurate numerical results. In this paper, study on the pricing of SPs with more stringent assumption which was the asset price obeying geometric Brownian motion assumption. But from "Parameter Determination" of this paper, asset price changed according to other laws, which required further research.

\section{CONFLICT OF INTEREST}

The authors confirm that this article content has no conflict of interest.

\section{ACKNOWLEDGEMENTS}

This work is supported by t National Natural Science Foundation of China (No. 71373029 and 70873012).

\section{REFERENCES}

[1] S. Das, Structured products \& hybrid securities, John Wiley \& Sons, 2001.

[2] K.C. Chen, and R.S. Sears, "Pricing the SPIN", Financail Management, vol. 19, pp. 36-47, 1990.

[3] A.H. Chen and J.W. Kensinger, "An analysis of market-index certificates of deposit", Journal of Financial Service Research, vol. 4, pp. 93-110, 1990.

[4] J.D. Finnerty, "Interpreting SIGNs:, Financial Management, vol. 22, pp. 33-47, 1993.

[5] S. Wilkens, P.A. Stoimenov, "The pricing of leverage products: an empirical investigation of the German market for "long"and "short" stock index certificates", Journal of Banking and Finance, vol. 31, pp. 735-750, 2007.

[6] M. Wallmeier and M. Diethelm, "Pricing of "exotic" Structured Products: The case of Multi-Asset Barrier Reverse Convertibles in Switzerland", Working Paper, 2008.

[7] R. Min and C. Jinlong, "A study on pricing of foreign exchange financial products with guaranteed equity-linked structure", Studies of International Finance, vol. 12, pp. 64-70, 2008.

[8] C. Jinlong and R. Min, "Study on pricing financial products of RMB with equity-linked guaranteed structure", Journal of Huaqiao University (Natural Science), vol. 31, pp. 342-345, 2010.

[9] C. Jinlong and R. Min, "Study on pricing financial products with guaranteed equity-linked structure based on the multi-asset", Journal of Management Sciences in China, vol. 14, pp. 64-70, 2011.

[10] G. Chang, "Martingale Pricing Research on one Kind of Convertible Bonds" Harbin Engineering University, China, pp. 39-40, 2011.

[11] T. Hui, Analysis of Influencing Factors of Commercial Banks' Personal Financial Products, Southwestern University of Finance and Economics, China, pp. 36-46, 2013.

[12] S.-N. Chen, Financial Engineering, Fudan University Press, Shanghai, 2002, pp. 37-43.

[13] P.G. Zhang, Exotic Options: A Guide to Second Generation Options, World Scientific Publishing, Singapore, 1994.

Received: March 13, 2015

Revised: May 07, 2015

Accepted: August 10, 2015

(C) Si-liang et al.; Licensee Bentham Open.

This is an open access article licensed under the terms of the (https://creativecommons.org/licenses/by/4.0/legalcode), which permits unrestricted, noncommercial use, distribution and reproduction in any medium, provided the work is properly cited. 